\title{
Article/Artigo
}

\section{Development of cognitive abilities of children infected with helminths through health education}

\author{
Desenvolvimento de habilidades cognitivas de crianças infectadas por helmintos através da \\ Educação em Saúde
}

\author{
Lucas Lobato ${ }^{1}$, Aline Miranda ${ }^{2}$, Isabela Marinho Faria ${ }^{3}$, Jeffrey Michael Bethony ${ }^{4,5}$ and Maria Flávia Gazzinelli ${ }^{6}$
}

\begin{abstract}
Introduction: The aim of this study was to evaluate the effect of health education in learning and cognitive development of children infected, previously treated in an endemic area for helminthiasis. Methods: It is a longitudinal, experimental, with random allocation of participants. The study included 87 children of both sexes enrolled in the school hall of Maranhão, State of Minas Gerais, Brazil, and divided into two groups: intervention and control. Initially the children were submitted to the parasitological fecal examination for infection diagnosis and, when positive, they were treated. For the data collection, a structured questionnaire and the psychological tests Raven, Wisc-III and DAP III were applied, before and after the educational intervention. For the group comparison, the Mann Whitney test was used, and established significance level of 5\%. Results: It was found that previously infected children who received the educational intervention, children showed higher performance than the control group in strutured questionnaire $(p<0.05)$. Conclusions: It is acceptable to suppose the positive influence and the importance in the use of educational interventions in the cognitive recovery and learning of children previously treated with anthelmintics.
\end{abstract}

Keywords: Learning. Children. Cognitive development. Health education. Helminthosis.

\section{RESUMO}

Introdução: $\mathrm{O}$ objetivo do estudo foi avaliar o efeito da educação em saúde na aprendizagem e desenvolvimento cognitivo de crianças infectadas, previamente tratadas, em área endêmica para helmintoses. Métodos: Trata-se de um estudo longitudinal, experimental e com distribuição aleatória dos participantes. Participaram do estudo 87 crianças, de ambos os sexos, matriculadas na escola municipal de Maranhão, Minas Gerais, Brasil, e distribuídas em dois grupos: intervenção e controle. Inicialmente, as crianças foram submetidas ao exame parasitológico de fezes para diagnóstico de infecção e, em caso positivo, foram tratadas. Para a coleta de dados, foi aplicado um questionário estruturado e os testes psicológicos Raven, Wisc-III e DFH III, antes e após intervenção educativa. Para a comparação entre os grupos foi utilizado o teste Mann Whitney e estabelecido nível de significância de 5\%. Resultados: Verificou-se que as crianças previamente infectadas, que receberam a intervenção educativa, apresentaram desempenho superior as crianças do grupo controle no questionário estruturado $(\mathrm{p} \leq 0,05)$. Conclusões: É aceitável supor a influencia positiva e a importância da utilização de intervenções educativas na recuperação cognitiva e aprendizagem das crianças previamente tratadas com antihelmínticos.

Palavras-chaves: Aprendizado. Crianças. Desenvolvimento cognitivo. Educação em saúde. Helmintoses.

1. Programa de Pós-Graduação em Enfermagem, Escola de Enfermagem, Universidade Federal de Minas Gerais, Belo Horizonte, MG. 2. Departamento de Nutrição, Centro Universitário Newton Paiva, Belo Horizonte, MG. 3. Escola de Enfermagem, Universidade Federal de Minas Gerais, Belo Horizonte, MG. 4. Departamento de Microbiologia, Imunologia e Medicina Tropical, Universidade George Washington, Washington, DC, USA. 5. Centro de Pesquisas René Rachou, Fundação Oswaldo Cruz, Belo Horizonte, MG. 6. Departamento de Imunologia, Escola de Enfermagem, Universidade Federal de Minas Gerais, Belo Horizonte, MG

Address to: Dr. Lucas Lobato. Programa de Pós-Graduação em Enfermagem/UFMG. Av. Alfredo Balena 190/ sala 508, 30130-100 Belo Horizonte, MG, Brasil

Phone: 5531 3409-9181; Fax: 5531 3409-9846

e-mail: lucaslobato87@gmail.com

Received in 06/12/2011

Accepted in 15/02/2012

\section{INTRODUCTION}

The soil-transmitted helminths infections are among the most common human infections. The World Health Organization (WHO) estimates that over two million people are infected with one or more soil-transmitted helminths, particularly Ascaris lumbricoides e Ancylostoma duodenalis ${ }^{1}$, being considered a public health problem in many countries.

In Brazil, as well as in other countries, the helminths infection rate is higher among children of school age ${ }^{2}$, particulary in Minas Gerais ${ }^{3,4}$. This situation is due to a large extent to the hygiene habits common to this age group and their immunity, which does not present maturity and competency to eliminate the parasites, condition even more aggravated in precarious socio-sanitary situations ${ }^{5}$.

Usually, children in school age who are infected with soil-transmitted helminths are physic and intellectually compromised due to malnutrition, leading to cognitive deficits, difficulties to learning and absenteeism in school ${ }^{6}$.

However, even though the clinical effects of the helminths infection are clearly described, the effects of the infection on the cognition and educational development are less clear ${ }^{7,8}$.

A revision study sought for evidences on the association between soil-transmitted helminths infections and the deleterious effects in children's development and cognition. They verified that most of 40 studies showed an association between the infection and the impairment of cognitive and educational abilities. Nevertheless, the majority of these studies have problems regarding the methodology and the control of confusion factors, such as: sex, age and socio-economic status? Therefore, it is acceptable to conclude that the nature of this relation is not clear due to the complexity of the interactions, but it does exist.

The resumption of the development of cognitive abilities possibly compromised because of the infection may occur with the anthelmintic treatment ${ }^{7}$. Regarding the cognitive development 
of children, highlight the positive effects of the administration of anthelmintics on memory and concentration ${ }^{10,11}$.

However, it is known that the removal of the cause may not be sufficient to restitute the affected abilities. Cognitive deficits may be irreversible or require a form of remediation in addition to the treatment ${ }^{9}$.

To enhance this recovery, Grantham-McGregor and Ani ${ }^{12}$ propose the addition of psychosocial and cognitive stimulation to the children after the anthelmintic treatment, which has demonstrated to be more significant than the isolated treatment.

In this respect, it is necessary to recognize that the development of the cognitive structures is a result of an experience that generates new structures that, in turn, links itself to specific knowledge pedagogies and methods that are nothing more than processes of agreements with which the educational interventions organize and develop themselves ${ }^{13}$.

In face of the possible repercussion of education in the development of cognitive competencies, we propose, in the present study, to evaluate the effect of education about health in the learning and cognitive development of infected children, previously treated, in helminths endemic areas.

\section{METHODS}

\section{Study design}

This study is characterized as experimental and longitudinal. The study was eight months long, totalizing nine interventions with each group, each one with average duration of three daily shifts. The phase previous to the educational interventions, when the data collection instruments were applied, was called time 1 , as time 2 was the phase when the interventions were concluded and the same instruments were again applied.

The children were randomly distributed among the groups education and control after chemotherapy for helminthes, whereby the first received educational interventions while the latter received interventions merely recreational.

After the educational intervention, we compared the performance on cognitive tests and psychological tests among subgroups healthy and infected who received (1) and did not receive educational intervention (2), as well as the comparison between the two subgroups infected(3) and healthy (4) (Figure 1).

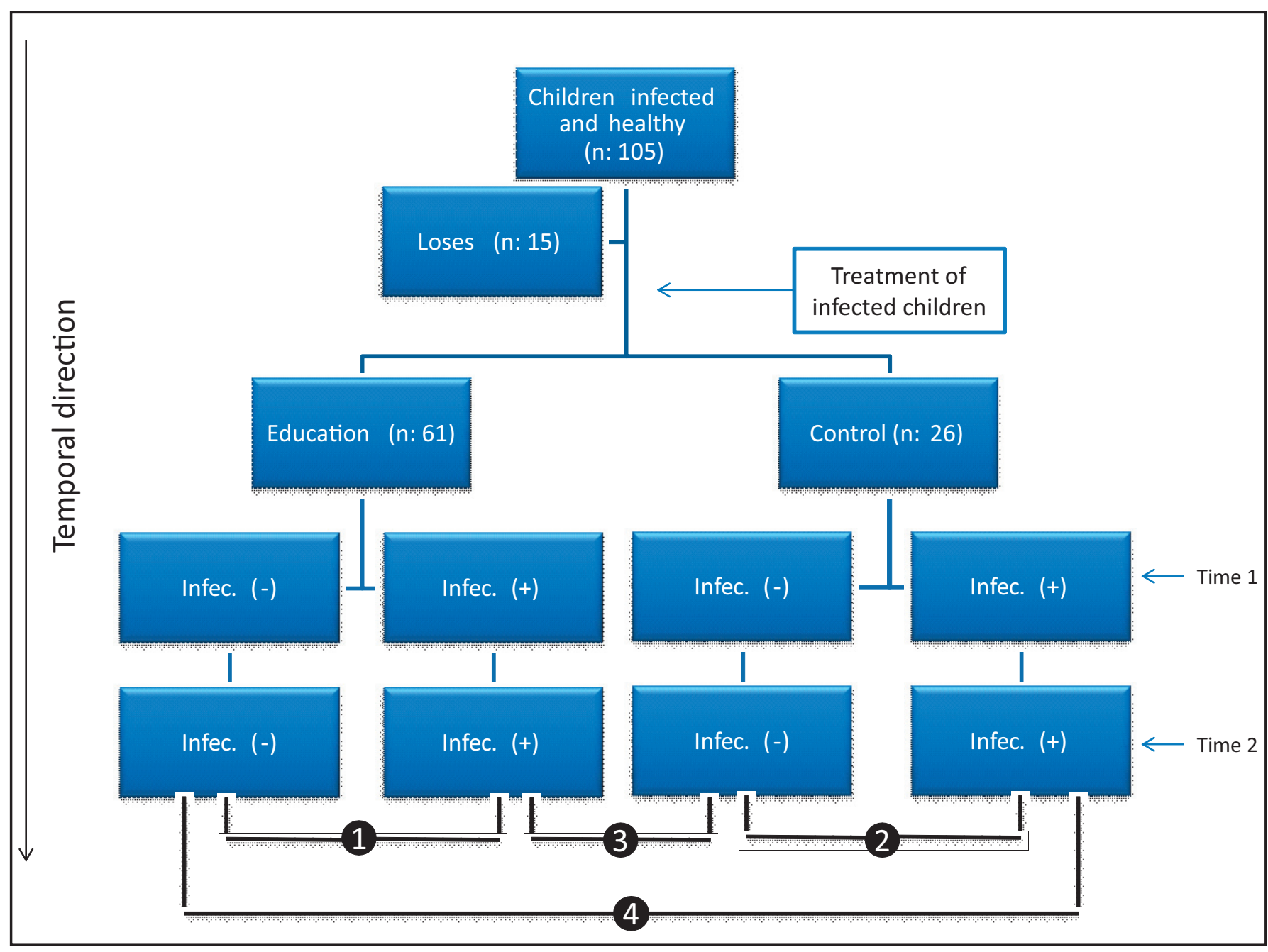

FIGURE 1 - Representation of the study design.

Infec (+): Children infected with helminthes; Infec (-): healthy children.

1: Comparison between healthy children and children infected with hookworm who did receive educational intervention; 2 : Comparison between healthy children and children infected with hookworm who did not receive educational intervention; 3: Comparison of hookworm-infected children who received the educational intervention and children who did not receive; 4: Comparison of healthy children who received the educational intervention and children who did not receive. 


\section{Study scenario}

The study was executed in Maranhão, rural area endemic for intestinal helminthiasis. It is a community located approximately 7 miles of Caraí, municipality, geographically situated in the Vale do Mucuri, located in the northeast of Minas Gerais, Brazil, where high rates of helminths infections can be found: $20 \%$ of ancylostomiasis, $24 \%$ of ascariasis and $30 \%$ of schistosomiasis. The educational activities were conducted in public school of the municipality of Maranhão (Escola Municipal $1^{\circ}$ de Maio - Municipal School $1^{\circ}$ de Maio) which receives students from preschool to high school, in morning, afternoon and night shifts.

\section{Study subjects}

The study included 105 children, of both sexes, frequent in the school activities at Municipal School $1^{\circ}$ de Maio from Maranhão community. The inclusion criteria were children 6 to 10 years old, enrolled in the referred school. During the study, 18 (17\%) children were lost due to one of the following factors: questionnaire and/ or psychological test not answered or inconclusive and absence of parasitological fecal examination. Out of this total, ten were allocated in the control group and 8 in the education group.

For participating in the study, the consent of the parents or custodians was given through the signature of Consent Informed.

\section{Data collection}

Parasitological fecal examination: the parasitological fecal examination (PFE) was performed in the two phases of the study. Three feces samples were collected of each participant of the study in three different moments. The empties were identified with the child's name, house number and identity number and the first of them was delivered to the families' houses. After referring the feces to the Health Center, the material was gathered and the researchers handed out a new empty for the collection of the second sample, being this procedure repeated until the conclusion of the third feces sample collection.

Structured questionnaire: the structured questionnaire aimed at evaluating learning, it had 20 questions regarding the knowledge about helminths, respective symptoms and prevention forms. Before the application of the questionnaire, a pilot test was executed in order to correct and adjust the instrument, which was later administered by graduation and post-graduation students, previously trained for this.

Psychological tests: the tests used were the Raven's Coloured Standard Progressive Matrices (CPM), the Draw-a-Person Test $3^{\text {rd }}$ edition (DAP-III) and four subtests from the Wechsler Intelligence Scale $3^{\text {rd }}$ edition (WISC-III) for children - Arithmetic, Digit, Code and Symbols Search, validated for the Brazilian population ${ }^{14-15}$.

We highlight that the choice for the CPM tests and the respective subtests from the Wechsler Intelligence Scale for children was due to their validation and standardization for the Brazilian population and for being broadly used in national studies ${ }^{16-19}$. The DAP-III was included in the study aiming at bringing relevant information about the cognitive development of the children.

All tests are authorized by the Conselho Federal de Psicologia (Psychology Federal Council), according to the Resolution 002/2003, Edicts n. 2 from 06.11.2003 and n. 3, from 28.11.2003.

All tests were individually executed by psychologists and Psychology students under the supervision of the first.

All the data collected from the structured questionnaires and psychological tests were tabulated in the SPSS program (Statistical
Package for Social Science - version 15.0). The data received double entry and, in case of difference between the two entries, the original questionnaire was reassessed for checking.

\section{Data analysis}

Parasitological fecal examination: the PFE was analyzed in the two phases of the study by the Kato-Katz method ${ }^{20}$. It is largely used and recommended for qualitative and quantitative diagnosis of helminthosis ${ }^{21}$. After this analysis, the children were divided in two groups, infected and healthy, each being composed by children with positive and negative results in this exam, respectively.

After this phase, the children who presented a positive result in the exam were treated. To evaluate the effectiveness of the treatment, three feces samples were again collected, 30 to 40 days after the previous stage, showing negativity in the diagnosis of helminthiasis for all these children.

Structured questionnaire and psychological tests: the descriptive analysis was performed for demographic variables using relative frequency for categorical variables and arithmetic mean for continuous variables. In order to ensure equivalence between the groups regarding the demographic characteristics the chi-square and the independent $t$ tests were performed, and a 5\% significance level was established. The chi-square test was used to verify the association of independent variables and the independent $t$ test to compare the age averages between the two groups.

After random allocation of subjects between groups and before the educational intervention was performed to compare the average of the psychological tests and structured questionnaire between intervention and control groups, the Mann Whitney test.

Subsequently, the variable average performance was created for the comparison intra-groups (infected and healthy in each group) and inter-group (infected-infected and healthy-healthy). This variable is the result of the difference between time 2 and time 1 from the average score from the structured questionnaire and the psychological tests.

As a variable that measures the scores, the median scores was chosen as a statistic model for comparison between the groups. Therefore, the scores average (percentage of scores) of each group was calculated, in time 1 and in time 2 .

The Mann-Whitney statistic non-parametric test was used for comparison between two medians. In all cases, a 5\% significance level was established.

\section{Ethical considerations}

This study was approved by the Ethics Committee on Human Research of the Federal University of Minas Gerais, under protocol protocol n. ETIC 0345.0.203.000-09, in 14/10/09

\section{RESULTS}

\section{Population characterization}

The mean of age of the participants was 8.45 years old $(1.69 \pm \mathrm{SD})$. Through Mann-Whitney test ( $5 \%$ significance level), it is observed that there was no statistically significant difference enters the average age of the intervention and control groups $(\mathrm{p}>0.05)$. Still, the chi-square test shows that there is no difference between the gender distribution and the groups $(p>0.05)$ 
Control group has 26 participants, 11 without previous infection for hookworms and 15 with previous infection with hookworm, while in the Intervention group has 61 people, distributed over 38 without previous infection for hookworms and 23 with previous infection with hookworm. The chi-square, it is inferred that there is no statistically significant difference between prior exposure to hookworm and distribution between the study groups ( $p>0.05)$.

\section{Relation between learning, cognitive development and infection}

Analysis of the median scores the educational intervention: there was no statistically significant difference between the infected and healthy children regarding prior knowledge about helminthosis and cognitive development $(\mathrm{p}>0.05)$.

Difference between the healthy and infected intra-groups performance: the results presented in Table 1 showed that there was no statistically significant difference between the performance of infected and healthy children from the education group regarding the knowledge about helminthosis and the psychological tests.

The results presented in Table 2 showed that there was no statistically significant difference between the performance of infected and healthy children from the control group regarding the knowledge about helminthosis and the psychological tests.

Difference between the performance of healthy and infected intergroups: we observed that there was no statistically significant difference between the scores from the psychological tests among the infected children from the education group and control group. However, we notice a statistically significant difference between the performances of the infected children who received the educational intervention and the ones from the control group in the structured questionnaire, highlighting the performance of the infected children received the educational intervention and higher than the control children (Table3).

TABLE 1 - Comparison of medians in the psychological tests and structured questionnaire from infected and healthy children from the education group.

\begin{tabular}{|c|c|c|c|c|c|c|c|c|}
\hline \multirow[b]{3}{*}{ Test } & \multicolumn{7}{|c|}{ Education group } & \multirow[b]{3}{*}{ p-value $^{b}$} \\
\hline & \multicolumn{3}{|c|}{ Ainfected (n=23) } & \multicolumn{3}{|c|}{ healthy $(n=38)$} & \multirow[b]{2}{*}{$\mathbf{z}^{\mathbf{a}}$} & \\
\hline & P25 & $\operatorname{Median}($ mean $\pm S D)$ & P75 & P25 & $\operatorname{Median}($ mean $\pm S D)$ & P75 & & \\
\hline Raven & $-20,0$ & $0,0(0.91 \pm 29.64)$ & 10,0 & $-20,0$ & $0(-2.78 \pm 32.36)$ & 15,0 & -0.396 & $>0.05$ \\
\hline Code & $-3,0$ & $1,0(-0.70 \pm 3.99)$ & 3,0 & $-2,0$ & $0(-0.41 \pm 3.28)$ & 2,0 & -0.330 & $>0.05$ \\
\hline Arithmetic & $-3,0$ & $1,0(-0.83 \pm 4.31)$ & 2,0 & $-1,25$ & $0,50(1.27 \pm 3.44)$ & 2,0 & -1.779 & $>0.05$ \\
\hline Digit & $-3,0$ & $0,0(0.04 \pm 3.34)$ & 3,0 & $-1,0$ & $1,0(0.59 \pm 2.18)$ & 2,0 & -0.802 & $>0.05$ \\
\hline SS & $-2,0$ & $1,0(0.39 \pm 2.95)$ & 2,0 & $-1,0$ & $2,0(1.32 \pm 2.74)$ & 3,25 & -1.433 & $>0.05$ \\
\hline DAP-III & $-3,0$ & $6,0(15.48 \pm 27.03)$ & 37,0 & $-2,0$ & $0,0(7.47 \pm 21.23)$ & 20,5 & -0.943 & $>0.05$ \\
\hline SC (\%) & 10,52 & $15,78(20.1 \pm 14.1)$ & 31,57 & 5,26 & $10,52(12.6 \pm 16.0)$ & 21,05 & -1.232 & $>0.05$ \\
\hline
\end{tabular}

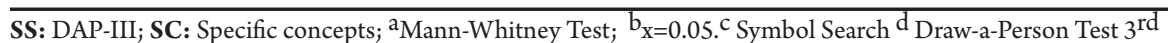

TABLE 2 - Comparison of medians in the psychological tests and structured questionnaire from infected and healthy children from the control group

\begin{tabular}{|c|c|c|c|c|c|c|c|c|}
\hline \multirow[b]{3}{*}{ Test } & \multicolumn{8}{|c|}{ Control } \\
\hline & \multicolumn{3}{|c|}{ infected $(n=15)$} & \multicolumn{3}{|c|}{ healthy $(n=11)$} & \multirow[b]{2}{*}{$\mathbf{Z}^{\mathbf{a}}$} & \multirow[b]{2}{*}{ p-value ${ }^{b}$} \\
\hline & P25 & $\operatorname{Median}($ mean $\pm S D)$ & P75 & P25 & $\operatorname{Median}($ mean $\pm S D)$ & P75 & & \\
\hline$\underline{\text { Raven }}$ & $-10,0$ & $0,0(-0.53 \pm 14.41$ & 15,0 & $-15,0$ & $-10,0(-9.09 \pm 22.03)$ & 9,0 & -0.396 & $>0.05$ \\
\hline Code & $-4,0$ & $-2,0(-1.53 \pm 3.89)$ & 1,0 & $-3,0$ & $-1,0(-1.36 \pm 3.67)$ & 1,0 & -0.330 & $>0.05$ \\
\hline Arithmetic & $-3,0$ & $0,0(-0.53 \pm 3.44)$ & 2,0 & $-3,0$ & $-1,0(0.01 \pm 2.65)$ & 2,0 & -1.779 & $>0.05$ \\
\hline Digit & $-2,0$ & $1,0(0.60 \pm 2.90)$ & 2,0 & $-4,0$ & $0,0(-0.55 \pm 2.94)$ & 2,0 & -0.802 & $>0.05$ \\
\hline SS & $-2,0$ & $1,0(-0.20 \pm 3.10)$ & 2,0 & $-2,0$ & $2,0(0.55 \pm 3.39)$ & 3,0 & -1.433 & $>0.05$ \\
\hline DAP-III & $-14,0$ & $0,0(0.47 \pm 15.66)$ & 9,0 & $-3,0$ & $-1,0(-4.00 \pm 23.18)$ & 5,0 & -0.943 & $>0.05$ \\
\hline SC (\%) & $-10,52$ & $10,52(5.7 \pm 18.1)$ & 21,05 & 5,26 & $10,52(8.7 \pm 14.3)$ & 21,05 & -1.232 & $>0.05$ \\
\hline
\end{tabular}

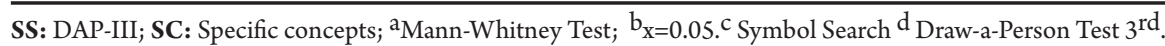

TABLE 3 - Comparison of medians in the psychological tests and in the structured questionnaire between infected children from the control and education groups.

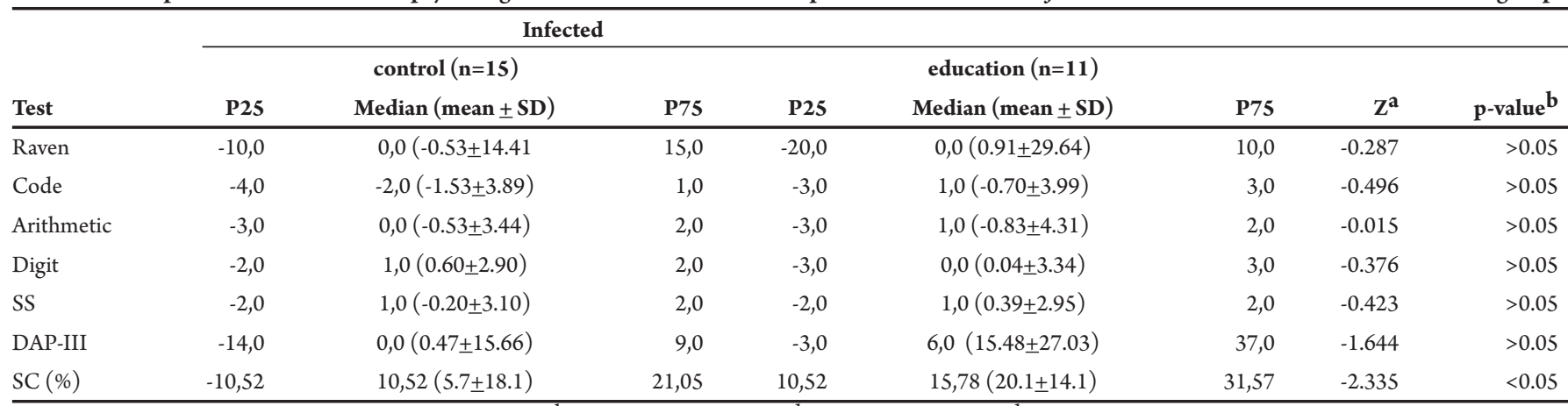

SS: DAP-III; SC: Specific concepts; ${ }^{\mathrm{a}}$ Mann-Whitney Test; ${ }_{\mathrm{x}=0.05 .}^{\mathrm{c}}$ Symbol Search ${ }^{\mathrm{d}}$ Draw-a-Person Test $3^{\text {rd }}$. 
TABLE 4 - Comparison of medians in the psychological tests and in the structured questionnaire between healthy children, from the control and education group.

\begin{tabular}{|c|c|c|c|c|c|c|c|c|}
\hline \multirow[b]{3}{*}{ Test } & \multicolumn{8}{|c|}{ Healthy } \\
\hline & \multicolumn{3}{|c|}{ control $(n=15)$} & \multicolumn{3}{|c|}{ education $(n=23)$} & \multirow[b]{2}{*}{$\mathbf{Z}^{\mathbf{a}}$} & \multirow[b]{2}{*}{ p-value $^{b}$} \\
\hline & P25 & $\operatorname{Median}($ mean $\pm S D)$ & P75 & P25 & $\operatorname{Median}(\operatorname{mean} \pm \mathbf{S D})$ & P75 & & \\
\hline Code & $-3,0$ & $-1,0(-1.36 \pm 3.67)$ & 1,0 & $-2,0$ & $0(-0.41 \pm 3.28)$ & 2,0 & -0.459 & $>0.05$ \\
\hline Arithmetic & $-3,0$ & $-1,0(0.01 \pm 2.65)$ & 2,0 & $-1,25$ & $0,50(1.27 \pm 3.44)$ & 2,0 & -1.170 & $>0.05$ \\
\hline Digit & $-4,0$ & $0,0(-0.55 \pm 2.94)$ & 2,0 & $-1,0$ & $1,0(0.59 \pm 2.18)$ & 2,0 & -1.201 & $>0.05$ \\
\hline SS & $-2,0$ & $2,0(0.55 \pm 3.39)$ & 3,0 & $-1,0$ & $2,0(1.32 \pm 2.74)$ & 3,25 & -0.618 & $>0.05$ \\
\hline DAP-III & $-3,0$ & $-1,0(-4.00 \pm 23.18)$ & 5,0 & $-2,0$ & $0,0(7.47 \pm 21.23)$ & 20,5 & -1.180 & $>0.05$ \\
\hline SC (\%) & 5,26 & $10,52(8.7 \pm 14.3)$ & 21,05 & 5,26 & $10,52(12.6 \pm 16.0)$ & 21,05 & -1.072 & $>0.05$ \\
\hline
\end{tabular}

SS: DAP-III; SC: Specific concepts; ${ }^{\mathrm{a}}$ Mann-Whitney Test; $\mathrm{b}_{\mathrm{x}=0.05}{ }^{\mathrm{c}}$ Symbol Search ${ }^{\mathrm{d}}$ Draw-a-Person Test ${ }^{\text {rd }}$.

It was observed that there was no statistically significant difference between the average performance from the individuals from the education and control groups in the psychological tests and in the structured questionnaire (Table 4). Despite the higher values in the education group, there were no values for $\mathrm{p}>0.05$.

We infer that, despite the educational intervention, there was no difference between the average performances of children who were not infected before the educational intervention.

\section{DISCUSSION}

The present study investigates the effect of education about health in the learning and cognitive development of infected children, previously treated, in helminths endemic areas.

Various procedures were adopted to minimize the occurrence of potential biases and assure the proper internal validity of the study. The concern with loss in the sample, present since the planning of the study, guided the implementation of actions aimed at minimizing the losses. However, the percentage of losses was moderate (17\%), especially due to difficulty in locomotion in this rural community to get the feces samples and the difficulty of some children in answering the research instruments.

The comparison between the remaining children's characteristics and the ones lost during the execution of the research did not show significant differences and thus conserved an essential characteristic for the study execution, the randomization of the children in the studygroups.

The children were enrolled in the same grade and studied in the same shift, besides living in the same region. Accordingly, it is not likely that differences among these characteristics might influence the study results, not compromising its internal validity.

Evaluation instruments of cognitive development considered more adequate to reach the established goals were used, especially due to the age factor. Also, a special attention was given to the execution of a pre-test in the structured questionnaire and to the adequate training of the interviewers.

Furthermore, the experience of the participant researchers of this study in similar researches in the same area corroborated to the construction of measure instruments, as well as their application.

Analyzing the results, we noticed that in the first moment of the study there was no significant difference regarding the cognitive and conceptual development between the infected and healthy children. This data contradicts our hypothesis of infected children presenting a weaker development, as well as the findings of some authors ${ }^{8}$. Another result that contradicts what we expected is the non-significant difference in the development of healthy and infected children from the education and group control.

Therefore, the conceptual development - the learning regarding the helminthosis - and the cognitive development of infected and healthy children submitted to the educational intervention were statistically similar, as well as that of the ones who were not submitted to the intervention, independently of the occurrence or non-occurrence of the previous parasitic infection.

Despite the control of various possible confusion factors, it is possible that a variable is able to explain these findings. The characteristic of the infection may be one of them. Data such as the worm which caused the infection, the presence or absence of multiple parasites and the parasitic load were not analyzed.

When comparing the individual effect of different parasites in the cognitive development of children, stated that not all cognitive domain analyzed, learning, memory, verbal fluency and non-verbal intelligence were affected, and also that different abilities were affected by different worms, the A. lumbricoides were associated to a weaker performance in the memory test and the T. trichiura was associated to a weaker performance in the verbal fluency tests ${ }^{22}$.

Some studies indicate that only moderate or high levels of infection may negatively affect the cognitive function, even further, positive effects of low levels of infection were found ${ }^{9}$.

Another probable explanation is that the time between the intervention and the application of the tests was not sufficient to the detection of changes. This hypothesis is reaffirmed by Drake ${ }^{9}$ and Ezeamana $^{22}$, who suppose that evaluations performed after a short period between the interventions, as has happened in some studies, may miss out the effects of the treatment. Considering what was exposed, it is likely that the possible cognitive deficits caused by the infections were not captured by the instruments used.

In the inter-group comparison, there was no significant difference in the development of healthy children from the control and education group regarding the structured questionnaire and the psychological tests. However, the infected children from the education group presented a better performance in the answer of the questionnaire when compared to the infected children from the control group.

We believe the children with helminths infection present the potential to benefit from the diminished environment. Therefore, after being treated and receiving the cognitive and educational remediation, they may reach a level of acculturation similar to the one acquired by other individuals ${ }^{23}$. As a result, we can infer that our educational intervention was efficient in stimulating the development of cognitive abilities, specifically the learning, of the children treated due to helminthosis. 
Another study that corroborates our findings is Walker ${ }^{24}$. They reviewed 16 researches about the evaluation of the cognitive stimulation effect in young children from developing countries. All interventions reported significantly higher rates of cognitive function in children who received additional cognitive stimulus or learning opportunities when compared to the control groups ${ }^{22}$.

From the results, it is possible to suppose the positive influence and the importance in using educational interventions in the cognitive and learning recuperation of children previously treated with anthelmintics.

This study may subsidize attention policies directed to the improvement of children's health conditions, particularly regarding the activation of their cognitive abilities to learning. These results are important because they show intestinal parasites still pose a public health problem, especially among children and in areas where socioeconomic conditions are less favorable and educational ${ }^{4}$.

The relevance of this study is especially highlighted when we consider the fact that the mental development and the rhythm of the individual intellectual progress constitute health attributes, due to the essential abilities for their insertion and functioning in society. In other words, insofar as it constitutes a limiting mechanism of this insertion, the development of the cognitive capacity becomes a matter of individual dimension with evident impact on the collective health.

\section{ACKNOWLEDGMENTS}

Thanks to everyone who, directly or indirectly participated in the preparation of this article and the construction of these results.

\section{CONFLICT OF INTEREST}

The authors declare that there is no conflict of interest.

\section{FINANCIAL SUPPORT}

This work was financially supported by the Human Hookworm Vaccine Initiative (HHVI) of the Albert B. Sabin Vaccine Institute (Washington, DC), which receives funding from the Bill \& Melinda Gates Foundation. The funder had no role in study design, data collection and analysis, decision to publish, or preparation of the manuscript. Lucas Lobato and Isabela Marinho Faria are fellowship from Coordenação de Aperfeiçoamento de Pessoal de Nível Superior.

\section{REFERENCES}

1. World Health Organization. Schistosomiasis and soil-transmitted helminth infections - preliminary estimates of the number of children treated with albendazole or mebendazole. Wkly Epidemiol Rec 2006; 81:145-163.

2. World Bank. School Deworming at a glance [Internet]. Public Health at a Glance Series, 2003[cited: 2011 May 1].Available from: http://www.worldbank.org/hnp/.

3. Ferreira P, Lima MR, Oliveira FB, Pereira MLM, Ramos LBM, Marçal MG, et al. Occurrence of intestinal parasites and commensal organisms among schoolchildren living in a 'landless farm workers' settlement in Campo Florido, Minas Gerais, State Brazil. Rev Soc Bras Med Trop 2003; 36:109-111
4. Gonçalves ALR, Belizário TL, Pimentel JB, Penatti MPA, Pedroso RS. Prevalence of intestinal parasites in preschool children in the region of Uberlândia, State of Minas Gerais, Brazil. Rev. Soc. Bras. Med Trop 2011; 44:191-193.

5. Melo EM, Ferraz FN, Aleixo DL. Importância do estudo da prevalência de parasitos intestinais de crianças em idade escolar. SaBios Rev Saude Biol 2010; 5:43-47.

6. Al-Mekhlafi MH, Surin J, Aiya AS, Ariffin WA, Mahdy AKM, Abdullah HC. Pattern and predictors of soil-transmitted helminth reinfection among aboriginal schoolchildren in rural Peninsular Malaysia. Acta Trop 2008; 107:200-204.

7. Grigorenko EL, Sternberg RJ, Jukes M, Alcock K, Lambo J, Ngorosho D, et al. Effects of antiparasitic treatment on dynamically and statically tested cognitive skills over time. J Appl Dev Psychol 2006; 27:499-526.

8. Sakti H, Nokes C, Hertanto WS, Hall A, Bundy DAP, Satoto. Evidence for an association between hookworm infection and cognitive function in Indonesian school children. Trop Med Int Health 1999; 4:322-334.

9. Drake LJ, Jukes MCH, Sternberg RJ, Bundy DAP. Geohelminthiasis (ascariasis trichuriasis and hookworm): cognitive and developmental impact. Semin Pediatr Infect Dis 2000; 11:245-251.

10. Hadidjaja P, Bonang E, Suyardi MA, Abidin SA, Ismid IS, Margono SS. The effect of intervention methods on nutritional status and cognitive function of primary school children infected with Ascaris lumbricoides. Baltimore: Am J Trop Med Hyg 1998; 59:791-795.

11. Nokes C, McGarvey ST, Shiue L, Wu G, Wu H, Bundy DA, et al. Evidence for an improvement in cognitive function following treatment of Schistosoma japonicum infection in Chinese primary schoolchildren. Am J Trop Med Hyg 1999; 60:556-565

12. Grantham-Mcgregor S, Ani C. A review of studies on the effect of iron deficiency on cognitive development in children. J Nutr 2001; 131:649-668.

13. Not L. As pedagogias do conhecimento. Américo EB, tradutor. Chapter 7. A educação cognitiva e o futuro dos alunos; $1^{\text {st }}$ ed. São Paulo: Difel; 1981.p. 448-449.

14. Angelini AL, Rosamilha N. Almeida RM. Manual de matrizes progressivas coloridas de Raven: escala especial. São Paulo: Centro Editor de Testes e Pesquisas em Psicologia; 1999.

15. Wechsler D. WISC-III: Escala de Inteligência Wechsler para Crianças: Manual. $3^{\text {rd }}$ ed. São Paulo: Casa do Psicólogo; 2002.

16. Bordin MBM, Linhares MBM, Jorge SM. Aspectos cognitivos e comportamentais na média meninice de crianças nascidas pré-termo e com muito baixo peso. Psic Teor Pesqu 2001; 17:49-57.

17. Botelho A, Raff S, Rodrigues RA, Hoffman HJ, Diemert DJ, Côrrea-Oliveira R, et al. Hookworm, Ascaris lumbricoides infection and polyparasitism associated with poor cognitive performance in Brazilian schoolchildren. Trop Med Int Health 2008; 13:994-1004.

18. Flores-Mendoza CE, Nascimento E. Condição cognitiva de crianças de zona rural. Estud Psicol 2007; 24:13-22.

19. Herzbert A, Mattar A. Instrumentos clínicos utilizados no Departamento de Psicologia Clínica da USP: 10 anos depois. Bol Psicol 2008; 58:39-54.

20. Katz N, Chaves A, Pellegrino J. A simple device for quantitative stool thicksmear technique in Schistosomiasis Mansoni. Rev Inst Med Trop 1972; 14:397-400.

21. Brasil MS. Plano Nacional de Vigilância e Controle das Enteroparasitoses. Brasília: Secretaria de Vigilância em Saúde; 2005.

22. Ezeamana AE, Friedman JF, Acosta LP, Bellinger DC, Gretchen C, Langdon DL et al. Helminth Infection and Cognitive Impairement among Filipino Children. Am J Trop Med Hyg 2005; 72:5401-5548.

23. Sternberg RJ, Mcgrane P, Powell C, Granthan-Mcgregor S. Effects of a Parasitic Infection on Cognitive Functioning. J Exp Psychol Appl 1997; 3:67-76.

24. Walker SP, Wachs TD, Gardner JM, Lozoff B, Wasserman GA, Pollit E, et al Child development: risk factors for adverse outcomes in developing countries [series]. Lancet 2007; 369:145-157. 